\title{
Reseña de Pavón (2019) Psicología crítica
}

\section{Lucero Mendoza Olguín ${ }^{1}$}

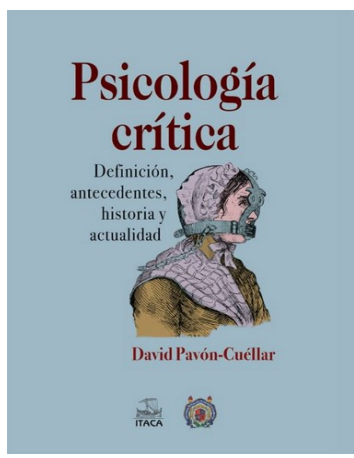

Pavón, David (2019). Psicología crítica. Definición, antecedentes, historia y actualidad. Ciudad de México: Ítaca; Universidad Michoacana de San Nicolás de Hidalgo.

Al finalizar la lectura de esta obra me he sentido por un lado satisfecha -ya comentaré por qué-y, por otro, curiosa de saber más de lo que aquí se nos muestra, con una especie de intención de lucha, de levantamien-

1 Universidad Cuauhtémoc de Aguascalientes, lucero_olguin@hotmail.com 
to, hablando, denunciando, invitando a otros a lo que a mis ojos invita Pavón-Cuéllar.

Quisiera comenzar por el afecto: satisfecha. ¿Por qué? En algún punto de la lectura, llegué a cuestio-narme si como estudiante de una licenciatura en psicología tuve algún acercamiento a la psicología crítica o a la crítica de la psicología. Satisfactoriamente, me he respondido que sí, pero sin saberlo en ese momento. Recuerdo que en aquellos años de forma-ción cruzamos algunos de los dilemas que la psicología podía plantearse desde su trinchera, como, por ejem-plo, la insistencia en la homogenización de las psico-logías.

Como estudiante, tuve la experiencia de reconocer algo que parecía una necesidad por parte de algunos docentes que evidentemente lo transmitían a sus estudiantes: acertar, encontrar una sola psicología, la que te hable de certezas, de universales, de apariencia científica, de definiciones más que de con-ceptos, de manuales con instrucciones muy puntuales, casi casi de oráculos a consultar para predecir las respuestas de los sujetos y disponer de un arsenal de técnicas con las cuales manipular esas respuestas hacia lo normal, adaptativo, funcional. Esa palabra, funcional, resonaba en poco más de la mitad de las asignaturas cursadas; el ideal a cumplir por parte de los sujetos era funcionar y el ideal a cumplir por parte de los psicólogos era hacer funcionar a esos sujetos, pero ¿qué se entendía por eso de la funcionalidad? Diría que trabajar o, mejor dicho, producir, escupir productos que la sociedad pudie- 
ra consumir de tal manera que algunos siguieran enriqueciéndose, en una lógica absolutamente capitalista. Si el sujeto no producía, no funcionaba, "no servía a la sociedad". Con frecuencia escuché comentarios como estos, en los que el sujeto era asumido como un producto más.

Recuerdo que era difícil cuestionar esa lógica; recuerdo que íbamos como por inercia sirviendo a ese fin. Si se trataba, por ejemplo, de la psicología del desarrollo del infante, en un taller de aplicación, había que detectar aquello que "no funcionaba normalmente" en el niño para modificarlo y hacer que cumpliera con los estándares, etiquetas de lo ideal que parecían haber surgido de la chispa ocurrente de los docentes porque ni siquiera mostraban una fundamentación teórica que soportara ese ideal. Y así navegábamos por las aguas turbias de la psicología, sin claridad sobre lo que se estaba haciendo y, en muchos de los casos, sin oportunidad de cuestionarlo, recibiendo y asumiendo el peso del encargo de regular socialmente a los sujetos. Al menos hasta que llegaron a nuestro alcance otros saberes, una especie de señal que si bien no indicaba el camino a seguir, sí mostraba pautas que permitían cuestionar nuestra posición como psicó-logos y el lugar de la psicología que hasta entonces se nos había mostrado.

Ahora puedo decir que fue en ese momento en el que supe de la crítica de la psicología a través de una antropología filosófica y una ética que me llevó a leer a 
filósofos como Schopenhauer y Nietzsche. Ahora puedo reconocer la labor de los docentes que confrontaban al grupo con debates sobre temas como la libertad. ¿La psicología libera al sujeto?, ¿cuál psicología lo libera y cuál lo encarcela?, ¿no será que la psicología sostiene discursos que nos sujetan a ideales capitalistas?

También supe de una psicología crítica a través del psicoanálisis, desde lo más ortodoxo como la interpretación de los sueños o la psicopatología de la vida cotidiana de Freud que hablaba de esas forma-ciones del inconsciente que exponen la verdad del sujeto y que muestran las ironías de la conciencia, hasta algo un poco más reciente con Lacan, que hablaba del significante y cómo el sujeto se encuentra atrapado en esas redes que le impone el Otro, con mayúscula. Y también recuerdo haber leído Psicología: ideología y ciencia (Braunstein, Pasternac, Benedito y Saal, 1975) que me llevó a preguntarme qué hace la psicología, por qué, para qué y a pedido de quién.

A pesar de recordar que la psicología crítica tuvo un lugar en las aulas de la universidad cuando yo estudié la licenciatura, tengo que reconocer que exis-tieron muchas dificultades para acercarnos a esos saberes y a esas preguntas. Desde luego, no era algo que tuviera cabida en el plan de estudios de la carrera. Además, la gran mayoría de los docentes que se oponían a que los alumnos nos adentráramos en algo que cuestionaba sus saberes y que no respondía a sus intenciones de 
universalidad, estandarización, cientifi-cismo y normalidad.

Dentro de las universidades, la psicología se ha convertido en una especie de tentáculo que trabaja para servir a una sociedad capitalista y neoliberal y que es necesario buscar la manera de incluir obras como la que reseño en este texto para acercar a los alumnos a un saber que no tiene pretensiones de homogeneidad y que, al contrario, proyecta caminos distintos en la psicología.

En esta obra de Pavón-Cuéllar sobre eso tan heterogéneo que llamamos psicología crítica, encontramos un recorrido que va de los antecedentes filosó-ficos, comenzando por una brevísima mención a los presocráticos - que a mi parecer inauguran una verda-dera acción filosófica cuestionando incisivamente sobre todo los asuntos de la naturaleza y de lo humanopara luego enlazarnos con filósofos clásicos como Platón y Aristóteles, que llamaron la atención sobre problemáticas específicos de lo psicológico como el dilema entre dualismo y monismo, problemática parti-cularmente interesante y siempre puesta sobre la mesa por todas sus implicaciones en el entendimiento del hombre, el psiquismo, el cuerpo. A partir de este problema, el autor nos conduce a otros pensadores: Spinoza, quien acepta una sola sustancia; Locke, quien dice que las ideas provienen de la experiencia; Leibniz, entendiendo que el pensamiento puede pasar desapercibido, sin que tengamos conciencia de él; y Kant, con su psi- 
cología racional. Así, va entrándose poco a poco en una lluvia incesante de preguntas sobre lo psicológico.

Entonces llegamos a una de las problemáticas que choca con las aspiraciones de homogeneidad de la psicología: la disparidad entre la disciplina y su objeto. Con esta problemática, Hegel y Herbart abrieron el camino hacia dos orientaciones: la científico-natural con Federico Alberto Lange y la hermenéutica-histórica con Wilhelm Dilthey, que fueron moldeando dos aristas importantes para la disciplina; es así como arribamos a Canguilhem quien ya puntualmente aborda la gran dificultad de homogeneizar la psicología, dificultad que, vista desde otra ángulo, bien podría suponer una cualidad deseable. Canguilhem expone claramente que homogeneizar la psicología es imposible, además de mostrar cómo es que el psicólogo no puede responder exactamente sobre lo que es y lo que hace, cuestiones que persisten en nuestros días.

El autor también nos habla de la necesidad de politizar la crítica. La psicología está inmersa en un mundo cultural, histórico, económico, social y político; Pavón-Cuéllar explica estos antecedentes desde la defensa de indios hasta el marxismo, el decolonialismo y el feminismo, intervenciones tanto teóricas como prácticas que influyen fuertemente en lo psicológi-camente abordable para mostrarnos el efecto de los poderosos en el pueblo, lo que luego se referirá en la trinchera latinoamericana como los de arriba y los de abajo, respectivamente. 
Siguiendo el recorrido por los antecedentes, llegamos a los fundadores de la psicología crítica. Lev Vygotsky discute sobre las corrientes psicológicas más importantes de la época y Georges Politzer expone los errores de la psicología: abstracción, formalismo, desparticularización, realismo y mitología. Ambos inau-guran una nueva acción psicológica, remover arenas, abrir brechas, iluminar los huecos que existen en las teorías y que otros buscan dejar desapercibidos para sostener eso que habríamos de llamar La Psicología con mayúsculas.

El recorrido sigue por muchas de las intervenciones, aristas, posiciones y propuestas de la psico-logía crítica. En el freudomarxismo destaca Wilhelm Reich, quien afirma que sin el marxismo el psicoanálisis tendería a volverse metafísico, idealista, burgués e individualista. Esta valoración me lleva casi por asociación libre a los postfreudianos, a quienes Lacan critica en el mismo sentido, usando el término exco-munión, que dice más de lo que aparenta (Lacan, 1964/2015).

Hablando de una herencia freudiana y marxista, Pavón-Cuéllar menciona la Escuela de Fráncfort, con los filósofos adscritos más conocidos: Max Horkheimer y Theodor Adorno exponiendo la animalización de los seres humanos. Precisamente esto me da pauta para hablar de la mercantilización de lo humano y, por ende, de lo psicológico. Recordemos también la aportación a esta escuela por parte de Georg Lukács, quien introduce el concepto de reificación. Justo en este apartado 
también encontramos el radicalismo psicoló-gico al que se refiere Francisco Gómezjara represen-tándolo desde su origen con Politzer y Reich para continuar con Fro$\mathrm{mm}$, Marcuse y Fanon, y ramificarse en autores diversos de la antipsiquiatría, por ejemplo, o la psicoterapia radical, destacando a Michel Foucault o Jacques Lacan, entre otros, autores que tienen en común la radicalidad crítica heterogénea.

Seguimos navegando por las mismas aguas pero en otros puertos, con el althusserianismo que también incluye la articulación entre marxismo y psicoanálisis, criticando la subordinación de la psicolo-gía a una ideología a través de la pasividad y dominación de un sujeto patologizado, subproducto de la psicoterapia. Menciona Pavón-Cuéllar que una de las elaboraciones de mayor alcance es la Psicología: ideología y ciencia de los argentinos exiliados en México: Néstor Braunstein, Marcelo Pasternac, Gloria Benedito y Frida Saal. Se trata de una de las obras de mayor alcance pues, como lo mencioné anteriormente, tuve un acercamiento con la misma durante la licenciatura que me hizo cuestionar asuntos como el rol del psicólogo, el encargo social y el carácter pseudo-científico de la psicología.

En la misma tradición de pensamiento, pero en Francia, el autor menciona a Michel Foucault y la forma en que discute el ejercicio del poder sobre la vida (biopolítica). Bastante interesante, diría yo, con alcances importantísimos también a través de obras como Historia de la locura, que a mi parecer poco a poco se va 
volviendo una obra de referencia obligada para los estudiantes de psicología. Y también en Francia, nos dice Pavón-Cuéllar, está Jacques Lacan. Como lectores, creo que podríamos conectarlo con la referencia que hace a Hegel, por ejemplo, cuando habla del deseo abordando la dialéctica del amo y del esclavo, o a Marx y Engels, que denuncian al discurso capitalista que cosifica al sujeto.

Hasta aquí es posible percibir una conexión cercana entre las distintas propuestas. Sin embargo existe una que, nos dice el autor, es "relativamente independiente" con respecto a las anteriores por permanecer en un modelo cerrado. Pavón se refiere a la psicología crítica de Klaus Holzkamp en Alemania que se basa principalmente en el pensamiento de Marx y expone la dominación de los sujetos a merced del sistema, mostrando cómo la psicología se abstrae del "mundo real" queriendo explicar lo psíquico por lo psíquico. Creo que en este punto también se introduce ese carácter pseudocientífico de la psicología que usa los conceptos para sí misma sin explicar la realidad en la que se inscribe el sujeto desde su verdad.

En otros lares, el paradigma posmoderno de la psicología social crítica habla de un valor que debería considerarse necesario para cada teoría y es el volverse críticamente hacia ella misma como hicieron Ibáñez e Íñiguez, no evadir o mucho menos ocultar los huecos que siempre existen en toda propuesta. En cualquier caso, como expone lan Parker, el paradigma posmo- 
derno entra en crisis por su desrealización de lo real, su abstracción de las condiciones sociales e históricas y su falta de posicionamiento político.

En la segunda mitad de la obra nos topamos con la trinchera latinoamericana y dos de sus orientaciones: la psicología social comunitaria impulsada por Maritza Montero y la psicología de la liberación fundada por Ignacio Martín-Baró. A su manera, ambas critican aspectos parecidos a los que ya se venían exponiendo. Lo que resalta sin embargo es la intención de cambio social, de contribuir a la liberación de los pueblos, lo que ya se había mencionado anteriormente: "la pers-pectiva realista de la crítica debe ser entonces la de abajo, la del pueblo oprimido, y no la de los opresores, no la de los sectores dominantes y las minorías pudientes, llámense burguesía o sectores medios, por la que suele regirse la psicología dominante" (Pavón-Cuéllar, 2019, p. 66). Es en este puerto, de este, mi lado del charco, donde he comenzado a experimentar un espíritu de lucha, de levantamiento hablado por medio de la denuncia, pero también un levantamiento a la praxis, a tomar partido en esta politización a la que no puede escapar la psicología crítica y a hacer, crear posibilidades, deconstruir y desujetarse del yugo dominante de los poderosos, de la mercanitlización de lo humano en esta sociedad capitalista y neoliberal.

Y con este espíritu vamos llegando a la psicología crítica de perspectiva marxista de lan Parker donde leemos un nuevo frente contra las ilusiones dominantes de 
la psicología como sirvienta del capitalismo. Parker tendería a "coincidir con Holzkamp al comprender cómo la psicología puede cambiar a medida que el capitalismo cambia y podrá volverse diferente una vez que el capitalismo deje de existir" (Pavón-Cuéllar, 2019, p. 68). Yo diría que en este punto hay una fantasía de acabar completamente con el capitalismo, difícil de realizar, quizás hasta imposible en estos momentos, pero creo que hay algo más importante que eso: el posicionamiento del cual habla Parker, el lugar que se va a asumir frente a esta lógica, que, si mal no recuer-do, también Zizek lo refiere, pues quizás más que la cuestión de si sí o no el capitalismo, se trata del cómo frente al capitalismo o frente a cualquier otro discurso Amo.

Para finalizar, podemos visitar cinco dilemas a los que se enfrenta la psicología crítica; todos demandan un momento para detenerse y pensar: ¿cuál será el efecto de uno u otro caso que se elija?, ¿cómo orientará esa decisión el camino de la psicología crítica?, ¿qué nuevas problemáticas pondrán interesan-te el rumbo de la disciplina?, ¿se podrá conjugar en la praxis lo que se propone en la teoría? o, más bien, ¿cómo llevarlo hasta ahí?, ¿no será que pueda tenerse el resultado contrario al que se espera?, ¿qué sorpresas surgirán de las posiciones que se asumen? Preguntas como estas son la base de la práctica de una psicología crítica, como en su definición mínima lo señala Pavón-Cuéllar. 
De esta manera, transcurriendo por las páginas de esta obra, es como me voy sintiendo curiosa pues voy encontrando algo así como una narración armoniosa que me introduce poco a poco en la gran cantidad de autores que han practicado abiertamente una psicología crítica, realizando propuestas sólidas para adentrarnos en la psicología dentro del mundo que hoy nos toca atravesar, un mundo que es, sobre todo, capitalista y neoliberal.

¿Homogeneizar la psicología? me preguntaba yo en las aulas universitarias, ¿a demanda de quién?, ¿con qué objeto?, ¿no es más rico y provechoso la heterogeneidad?, y encontré ya hace tiempo la respuesta: sí que lo es y con esta obra la sorpresa mía es que hay más heterogeneidad de la que podía imaginar y que hay más propuestas ricas y prove-chosas para agilizar la mente, poner temas sobre la mesa, discutir, cuestionar, incomodar y también reo-rientar nuestra disciplina.

Sintiendo esa intención de lucha, de levanta-miento hablado, hablando, denunciando, ahora sí res-pondo a la invitación: ja hacer psicología crítica!

\section{Referencias}

Braunstein, N., Pasternac, M., Benedito, G. y Saal, F.

(1975). Psicología: ideología y ciencia. México: Siglo XXI. 
Lacan, J. (1964/2015). El seminario. 11: Los cuatro conceptos fundamentales del psicoanálisis. Buenos Aires: Paidós.

Pavón, D. (2019). Psicología crítica. Definición, antecedentes, historia y actualidad. Ciudad de México: Ítaca; Universidad Michoacana de San Nicolás de Hidalgo.

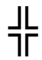




\section{(c) (1) Q8)}

Esta obra está bajo una

Licencia Creative Commons Atribución-NoComercial-Compartirlgual 4.0 Internacional

Usted es libre de compartir o adaptar el material en cualquier medio o formato bajo las condiciones siguientes: (a) debe reconocer adecuadamente la autoría, proporcionar un enlace a la licencia e indicar si se han realizado cambios; (b) no puede utilizar el material para una finalidad comercial y (c) si remezcla, transforma o crea a partir del material, deberá difundir sus contribuciones bajo la misma licencia que el original.

Resumen de la licencia https://creativecommons.org/licenses/by-nc-sa/4.0/deed.es_ES

Texto completo de la licencia https://creativecommons.org/licenses/by-nc-sa/4.0/legalcode 